\title{
Investigating Women's and Men's Propensity to Use Traffic Information in a Developing Country
}

\author{
Fatemeh Baratian-Ghorghi ${ }^{1}$ (1) $\cdot$ Huaguo Zhou $^{1}$
}

Received: 20 January 2015 / Accepted: 17 June 2015/Published online: 24 June 2015

(C) Springer International Publishing AG 2015

\begin{abstract}
Congestion problems and their vast negative effects on transportation networks are at the center of transportation providers' attention. Considering the high costs associated with extending highway networks, using transportation demand management (TDM) strategies to alleviate congestion is a more cost-effective approach; however, planning and implementing TDM policies and strategies, in particular, necessitate careful examination and detailed analysis of commuter behavior and tendencies. Providing traffic condition information via radio to guide drivers through less congested paths is one common method of low-cost TDM in developing countries. The objective of this paper is to study the different behaviors between men and women in responding to traffic information that they receive by radio, as a part of advanced invehicle systems. In order to conduct this study, a random sample of drivers was surveyed to investigate their travel behaviors and responses while they were exposed to traffic information obtained through radio. Each gender response was studied separately to examine any possible differences in their propensity to use traffic information. In doing so, the ordered logit model was designated and NLOGIT package was used. The final results showed that age, driving time, listening to radio traffic information, preferred arrival time at workplace, and delay time variables in both men's and women's models were in common, but education and occupation were identified as significant in
\end{abstract}

Fatemeh Baratian-Ghorghi

baratian@auburn.edu

Huaguo Zhou

zhouhugo@auburn.edu

1 Department of Civil Engineering, Auburn University, Auburn, AL 36849-5337, USA the females' behavior only, and income and car ownership were significant for males. It is expected that appropriate decisions in recognition of these study results should be made to develop more effective traffic information for different users.

Keywords Radio - Traffic information - Travel behavior . Ordered logit model $\cdot$ Nlogit $\cdot$ Advanced traveler information systems

\section{Introduction}

The importance and urgency of traffic congestion problems-especially due to their consequences, such as the fuel crisis and pollution impacts-cannot be underestimated. This issue has been approached in various ways. In recent years, the demand and supply management policies and strategies have been considered useful ways to solve such problems due to their lower costs compared to highway construction [1]. In congested networks, advanced traveler information systems (ATIS) support several traveler choices, such as selection of destination, mode, route, departure time, intermediate stops, and parking. Providing drivers with important traffic information via radio reports in order to decrease congestion on the roads is the most feasible solution that is also practical and economical.

One of the best ways to inform travelers about traffic conditions is to use technologies, such as a radio traffic information system, to allow access to travel information for almost all drivers. The common objective of this system is to deliver necessary information to assist individual drivers with optimal route identification based on the realtime information of current/predicted traffic conditions. This system, named "Radio-Payam" in Tehran, Iran, 
broadcasts traffic reports, including descriptions of overall traffic conditions on the main corridors, traffic jam location and their clearance, and recommended alternative routes.

Even though this accessible information can help influence some driving decisions, travel behavior is also influenced by a variety of factors, with gender as one of the most common forms of demographic segmentation because of the difference in activities among genders. In general, it has been proven that males and females process information and make decisions differently [2-5]. This discovery necessitates that each gender's travel behaviors be evaluated over time to determine whether they have similar travel patterns or not. In this study, differences in travel behavior are investigated on the basis of disparity in the level of agreement with radio reports. In particular, the travel behaviors of men and women are compared in terms of reactions to the information. The present study seeks to identify the factors affecting the importance of radio traffic information for male and female commuters separately.

\section{Literature Review}

On November 18-20, 2004, Transportation Research Board (TRB) held its third conference in Chicago, Illinois, with an interest in advancing the understanding of women's issues in transportation [6]. One of the presented studies, conducted by Nobis et al. [4], revealed that the gender difference in travel patterns is linked to employment status, household structure, child-care responsibilities, and maintenance tasks. They found that travel patterns of men and women are more similar in single-parent families; the differences are greater when males and females are compared in multi-person households without children; and they are the highest when they live in households with children. Over the past two decades, numerous studies have been conducted on travel behavior, showing gender as an influential factor in travel decisionmaking [2-5, 7-10].

Many other studies have been conducted to address the evaluation of the diverse traffic information systems, their effects on travelers' behavior, and their effectiveness from the drivers' perspective [11-22]. Some of them found gender is an effective factor in influencing drivers' preference and response [11, 19-22], while few studies showed that females and males were not significantly different [14].

Table 1 contains a summary of eight related studies in five different countries. Most studies used the survey method for data collection and the statistical modeling for data analysis.

\section{Questionnaire Design and Surveys Sampling}

The analyses in this study were based on the data gathered from a questionnaire designed for this project. In the questionnaire, there were 16 questions asking about drivers' socioeconomic characteristics and their opinion concerning traffic reports. In addition to multiple-choiceanswer questions, several direct questions were asked concerning such subjects as level of education, job category, marital status, and work start and end time. The survey used in this study was done and provided by the Research Deputy of Sharif University of Technology. Some other studies used the same form to collect their required data $[23,24]$. The survey questionnaires were distributed to the passenger car drivers by hand on the main corridors in Tehran, the capital city of Iran. A usable sample of 404 resident drivers (279 men and 125 women) was received by mail after 4 weeks. Even though a random sample of drivers was surveyed, the sample size adequately reflects the proportion of male-to-female drivers in Tehran because females drive less often than males there.

The minimum age for driving is 18 years old. So, the respondents' age are greater than 18. 404 drivers took the survey of which $59 \%$ fell in the 18-45 years old range and $41 \%$ were older than 45 . The percentage of observations that exist for other groups of variables are as follows: (1) In terms of education, $40 \%$ of the respondents had never graduated from college and $60 \%$ were college graduates or had some postgraduate education; (2) In terms of employment status, $60 \%$ were company employees, $4 \%$ were taxi drivers, $13 \%$ claimed to be self-employed salesman, and $23 \%$ had other types of employment; (3) In terms of marital status, $20 \%$ of respondents were single and $80 \%$ were married; (4) In terms of vehicle ownership, $95 \%$ owned vehicles and $5 \%$ did not.

\section{Modeling}

\section{Dependent and Independent Variables}

The main objective of this study was to determine the factors that influence drivers' propensity to use traffic information (e.g., route changes, construction activities, and road accidents). The three dependent variables (Y) to be modeled were the answers to the three parts of the questionnaire's number 15 in which drivers were asked if they would pay attention to alternative-routes announcements, executive-operation announcements, and car-accident announcements that indicate a work zone downstream on their way to/from work. Those surveyed answered using 
Table 1 Reviewed studies

\begin{tabular}{|c|c|c|c|c|}
\hline Authors & Location & Purpose of study & Method & Findings \\
\hline $\begin{array}{l}\text { Emmerink } \\
\text { et al. [11] }\end{array}$ & $\begin{array}{l}\text { Amsterdam, } \\
\text { The } \\
\text { Netherlands }\end{array}$ & $\begin{array}{l}\text { Analyzing the impact of both radio } \\
\text { traffic information and variable } \\
\text { message sign (VMS) information on } \\
\text { route choice behavior }\end{array}$ & $\begin{array}{l}\text { Ordered probit, multiple } \\
\text { logit and bivariate } \\
\text { ordered probit models }\end{array}$ & $\begin{array}{l}\text { Women are less likely to be influenced by } \\
\text { traffic information. Level of satisfaction } \\
\text { with alternative routes is strongly related } \\
\text { to the type and distance of route }\end{array}$ \\
\hline $\begin{array}{l}\text { Bagloee } \\
\text { et al. [12] }\end{array}$ & Tehran, Iran & $\begin{array}{l}\text { Analyzing how the radio traffic } \\
\text { information influences drivers' route } \\
\text { choice behavior }\end{array}$ & $\begin{array}{l}\text { Discrete choice method as } \\
\text { well as Artificial } \\
\text { Intelligence models }\end{array}$ & $\begin{array}{l}\text { Company employees and troopers have } \\
\text { more tendencies to alter their routes } \\
\text { Middle-aged drivers with 5-20 min PAT } \\
\text { take an alternate route less often }\end{array}$ \\
\hline $\begin{array}{l}\text { Tseng } \\
\text { et al. [13] }\end{array}$ & $\begin{array}{l}\text { Amsterdam, } \\
\text { The } \\
\text { Netherlands }\end{array}$ & $\begin{array}{l}\text { Investigating the impacts of traffic } \\
\text { information on traveler behavior }\end{array}$ & $\begin{array}{l}\text { Estimating a revealed- } \\
\text { preference scheduling } \\
\text { model }\end{array}$ & $\begin{array}{l}\text { Provision of traffic information has effects } \\
\text { on traveler behavior }\end{array}$ \\
\hline $\begin{array}{l}\text { Zhong } \\
\text { et al. [14] }\end{array}$ & $\begin{array}{r}\text { Beijing, } \\
\text { China }\end{array}$ & $\begin{array}{l}\text { Evaluating the impact of different } \\
\text { factors on driver's guidance } \\
\text { compliance behavior in relation to } \\
\text { VMS information }\end{array}$ & Ordinal regression by SPSS & $\begin{array}{l}\text { Age, driving experience, income, } \\
\text { occupation, trusting in the system, and } \\
\text { route choice style are some influencing } \\
\text { factors }\end{array}$ \\
\hline $\begin{array}{l}\text { Gan et al. } \\
\text { [15] }\end{array}$ & $\begin{array}{l}\text { Shanghai, } \\
\text { China }\end{array}$ & $\begin{array}{l}\text { Investigating the effect of factors on } \\
\text { driver's route choice in response to } \\
\text { VMS travel time information }\end{array}$ & $\begin{array}{l}\text { Using generalized } \\
\text { estimating equations } \\
\text { (GEEs) method }\end{array}$ & $\begin{array}{l}\text { Driving years, expressway delay, cause of } \\
\text { delay, signalized intersections affect } \\
\text { route choice behavior } \\
\text { The response behavior is different based } \\
\text { on the type of vehicle }\end{array}$ \\
\hline $\begin{array}{l}\text { Khoo and } \\
\text { Ong [16] }\end{array}$ & $\begin{array}{l}\text { Klang } \\
\text { Valley, } \\
\text { Malaysia }\end{array}$ & $\begin{array}{l}\text { Evaluating the effectiveness, level of } \\
\text { awareness, and use of various traffic } \\
\text { information tools }\end{array}$ & $\begin{array}{l}\text { Conducting revealed } \\
\text { preference survey and } \\
\text { using discrete choice } \\
\text { models }\end{array}$ & $\begin{array}{l}\text { The lesser impacts are for driver's } \\
\text { demographics and the most for trip } \\
\text { characteristics. Drivers do not have trust } \\
\text { in the systems }\end{array}$ \\
\hline $\begin{array}{l}\text { Jiang et al. } \\
\text { [17] }\end{array}$ & $\begin{array}{l}\text { Changchun, } \\
\text { China }\end{array}$ & $\begin{array}{l}\text { Analyzing dynamic traffic information } \\
\text { systems (radio and VMS) and } \\
\text { driver's responses }\end{array}$ & $\begin{array}{l}\text { Qualitative and statistical } \\
\text { methods }\end{array}$ & $\begin{array}{l}\text { Congestion and alternative route } \\
\text { announcements are most important } \\
\text { Listening to radio and level of education } \\
\text { positively impact behaviors }\end{array}$ \\
\hline $\begin{array}{l}\text { Kattan } \\
\text { et al. [18] }\end{array}$ & $\begin{array}{l}\text { Calgary and } \\
\text { Alberta, } \\
\text { Canada }\end{array}$ & $\begin{array}{l}\text { Investigating travel behavior change in } \\
\text { response to traffic information }\end{array}$ & $\begin{array}{l}\text { Survey on a sample of } \\
\text { drivers was conducted to } \\
\text { collect and analyze self- } \\
\text { reported changes }\end{array}$ & $\begin{array}{l}\text { Radio is the most preferred source of } \\
\text { information. Demographic factors do not } \\
\text { have influence on changing decisions }\end{array}$ \\
\hline
\end{tabular}

Q15- In the case of presenting following announcements, will you pay attention to them?

\begin{tabular}{|c|lccc|}
\hline Alternative route announcement & $\square$ Not at all $\quad \square$ little $\quad \square$ moderate $\quad \square$ much $\quad \square$ so much \\
\hline Construction activity announcement & $\square$ Not at all $\quad \square$ little $\quad \square$ moderate $\quad \square$ much $\quad \square$ so much \\
\hline Road accident announcement & $\square$ Not at all $\square$ little $\quad \square$ moderate $\quad \square$ much $\quad \square$ so much \\
\hline
\end{tabular}

Fig. 1 Question 15

a 5-point scale ranging from "not at all" to "so much" (Fig. 1).

In order to reduce the risk of errors in posing and interpreting questions, the responses were aggregated and reduced to three: "little or none" (the combination of 1 and 2), "moderately" (3), and "a lot" (the combination of 4 and 5).

The explanatory variables $(\mathrm{X})$ consist of both variables directly extracted from the survey's questions and combined variables. The independent variables belong to one of the following groups: individual socioeconomic characteristics (e.g., age, sex, education, job category, and marital status), listening to traffic radio reports, work trip characteristics (e.g., distance and travel times), and job characteristics (e.g., preferred arrival time, work start and end time, and the permitted late arrival time at work). To demonstrate the effect of nonlinear variables, such as age or level of education, dummy variables are used. In the survey, commuters reported their PAT and permitted delay time in terms of minutes before and after the official work start time. PAT, which is a measure of the commuters' risk attitudes variable, reflects a safety margin to 
avoid lateness [25]. In this study, PAT was combined with various levels of permitted late arrival at work to make new categories of commuters who take a certain level of risk. The combination of variable PAT of less than $15 \mathrm{~min}$ and delay time was known as the indicator of risky persons, while PAT of more than 15 min combined with different levels of permitted late arrival indicated the group of non-risky persons.

\section{Ordered Response Models}

Since the concept modeled is ordinal by nature, the ordered response model seemed to be the proper tool for this study [26]. The underlying assumption for ordered response models is that there is an unobserved dependent variable (latent variable $\mathrm{Y}^{*}$ ), which varies between $-\infty$ to $+\infty$, representing respondent i's propensity to agree with the statement offered [27]. The latent "preference" variable, $\mathrm{Y}_{\mathrm{i}}{ }^{*}$, is not observed. The observed counterpart to $\mathrm{Y}_{\mathrm{i}}{ }^{*}$ is $\mathrm{Y}_{\mathrm{i}}$ that is the individual i's response to the survey question, which can take one of the integer values $0,1,2,3, \ldots, \mathrm{n}$. The general structure of ordered model is:

$\mathrm{Y}_{\mathrm{i}}^{*}=\beta \mathrm{X}_{\mathrm{i}}+\mathrm{u}_{\mathrm{i}}, \quad \mathrm{i}=1, \ldots, \mathrm{n}$

where $i$ is the index for the observation/respondent, $\mathrm{n}$ the number of observations/respondents, $\mathrm{Y}_{\mathrm{i}}{ }^{*}$ the $i$ th unobserved dependent variable, $X_{i}$ the vector of explanatory variables for the $i$ th observation, $\beta$ the vector of model parameters, $\mathrm{u}_{\mathrm{i}}$ the random segment of observation $i$.

The ordered logit model arises if $u_{i}$ is assumed to have a logistic distribution. The variance of $u_{i}$ is assumed to be the standard (i.e. $\pi^{2} / 6$ for the logit model [28]). However, $Y^{*}$ is unobserved; so the relationship between $Y^{*}$ and the observed variable $Y$ is:

$\mathrm{Y}_{\mathrm{i}}=\mathrm{m}$ if and only if $\mu_{\mathrm{m}-1} \leq \mathrm{Y}_{\mathrm{i}}^{*}<\mu_{\mathrm{m}}$

for $\mathrm{m}=1, \ldots, \mathrm{J}, \mathrm{i}=1, \ldots, \mathrm{n}$

$\mu$ is the threshold parameter, which defines the ranges of $\mathrm{Y}_{\mathrm{i}}{ }^{*}$ associated with each discrete value of $\mathrm{Y}_{\mathrm{i}}$. The probabilities associated with the observed outcomes are:

$$
\begin{aligned}
\operatorname{Pr}\left(\mathrm{Y}_{\mathrm{i}}=\mathrm{m} \mid \mathrm{X}_{\mathrm{i}}\right) & =\operatorname{Pr} \mu_{\mathrm{m}-1}<\mathrm{Y}_{\mathrm{i}^{*}} \leq \mu_{\mathrm{m}} \mid \mathrm{X}_{\mathrm{i}} \\
& =\operatorname{Pr} \mu_{\mathrm{m}-1}<\beta \mathrm{X}_{\mathrm{i}}+\mathrm{u}_{\mathrm{i}} \leq \mu_{\mathrm{m}} \\
& =\operatorname{Pr} \mu_{\mathrm{m}-1}-\beta \mathrm{X}_{\mathrm{i}}<\mathrm{u}_{\mathrm{i}} \leq \mu_{\mathrm{m}}-\beta \mathrm{X}_{\mathrm{i}} \\
& =\mathrm{F}\left(\mu_{\mathrm{m}}-\beta \mathrm{X}_{\mathrm{i}}\right)-\mathrm{F}\left(\mu_{\mathrm{m}-1}-\beta \mathrm{X}_{\mathrm{i}}\right)
\end{aligned}
$$

$F(u)$ is the logistic cumulative distribution function. With the assumption of independent observations, the likelihood function for the basic ordered choice model is:

$$
\begin{aligned}
\mathrm{L}(\beta, \mu / \mathrm{Y}, \mathrm{X}) & =\prod_{\mathrm{j}=1}^{J} \prod_{i=1}^{n} \operatorname{Pr}\left(Y_{i}=j \mid X_{i}, \beta, \mu\right) \\
& =\prod_{\mathrm{j}=1}^{J} \prod_{\mathrm{i}=1}^{n} F\left(\mu_{j}-\beta X_{i}\right)-F\left(\mu_{\mathrm{j}-1}-\beta X_{i}\right)
\end{aligned}
$$

Since the optimal points of this probability function and its logarithm function are equal, log likelihood function is used most of the time, which is more efficient:

$$
\begin{aligned}
\mathrm{L}^{*} & =\ln \mathrm{L}\left(\beta, \mu \mid \mathrm{Y}_{\mathrm{i}}, \mathrm{X}\right) \\
& =\sum_{\mathrm{j}=1}^{\mathrm{J}} \sum_{\mathrm{i}=1}^{\mathrm{n}} \ln \left[\mathrm{F}\left(\mu_{\mathrm{j}}-\beta \mathrm{X}_{\mathrm{i}}\right)-\mathrm{F}\left(\mu_{\mathrm{j}-1}-\beta \mathrm{X}_{\mathrm{i}}\right)\right]
\end{aligned}
$$

The restricted log likelihood $\left(L^{*}\right)$ is computed for a model in which a constant parameter is the only dependent variable. In this situation, utility of responses are equal and called null hypothesis model.

$\mathrm{L}^{*}(0)=-N \ln (1 / \mathrm{I})$

where $\mathrm{N}$ is the number of observations and $\mathrm{I}$ is the number of responses (i.e. 3). Iteration 0 is a model in which all of the slope parameters are set to zero and the first log-likelihood value is the restricted log-likelihood $(\mathrm{L}(\mathrm{R}))$.

In this study, we took advantage of the $t$ test to determine the significance of each explanatory variable in a $90 \%$ confidence interval and Chi squared test to evaluate models. L(R) was compared with the maximized loglikelihood $(\mathrm{L}(\mathrm{F}))$ in a Chi squared test to evaluate the overall significance of the explanatory factors. The Chi squared equation for two $\mathrm{F}$ and $\mathrm{R}$ models (which $\mathrm{F}$ contains more parameters than $\mathrm{R}$ ) is equivalent to:

$-2[\mathrm{~L}(\mathrm{R})-\mathrm{L}(\mathrm{F})] \sim \chi^{2} \mathrm{df}$

where $d f$ denotes the degrees of freedom, defining the difference between the number of parameters in two models.

\section{Results and Model Specifications}

The results of the ordered logit models, using NLOGIT Software, are presented in Tables 2 and 3. In the early phases of modeling, the Forward/Backward Selection method was used as a means to help with identifying significant variables. Variables were entered one-by-one into the model, and their significance was determined using the t-test. Later, those variables seemed important based on theoretical concerns, and the experience of other researchers as reported in the literature was considered, as well. Also, only relevant responses to the three parts of question 15 were brought into the discrete choice models. 
Table 2 Results of modeling women's propensity to pay attention to the announcements

\begin{tabular}{|c|c|c|c|c|c|c|}
\hline \multirow[t]{2}{*}{ Variable description } & \multicolumn{2}{|c|}{$\begin{array}{l}\text { Alternative route } \\
\text { announcement }\end{array}$} & \multicolumn{2}{|c|}{$\begin{array}{l}\text { Construction activity } \\
\text { announcement }\end{array}$} & \multicolumn{2}{|c|}{$\begin{array}{l}\text { Road accident } \\
\text { announcement }\end{array}$} \\
\hline & Coefficient & $\mathrm{t}$ value & Coefficient & $\mathrm{t}$ value & Coefficient & $\mathrm{t}$ value \\
\hline Constant & 4.805 & 4.156 & 52.01 & 3.671 & 4.614 & 2.614 \\
\hline Listening to radio & & & & & 2.81 & 2.625 \\
\hline Driving time (Logarithm) & & & -3.268 & -2.533 & & \\
\hline Educational level & & & 2.627 & 2.43 & 1.592 & 1.87 \\
\hline \multicolumn{7}{|l|}{ Age } \\
\hline$<30$ & 1.72 & 2.035 & & & & \\
\hline \multicolumn{7}{|l|}{ Occupation } \\
\hline Company employee & & & 1.918 & 1.884 & & \\
\hline \multicolumn{7}{|l|}{ Delay time } \\
\hline Any delay is permitted & & & & & -3.394 & -2.685 \\
\hline \multicolumn{7}{|l|}{ Preferred arrival time } \\
\hline \multicolumn{7}{|l|}{ Risky } \\
\hline $\mathrm{PAT}<15 \mathrm{~min}$ & & & & & -1.837 & -1.881 \\
\hline PAT $<15 \mathrm{~min}$ and delay time $<5 \mathrm{~min}$ & -3.214 & -3.099 & & & & \\
\hline $\mathrm{PAT}<15 \mathrm{~min}$ and delay time $5-15 \mathrm{~min}$ & & & -2.701 & -2.287 & & \\
\hline $\mathrm{PAT}<15 \mathrm{~min}$ and delay time $>15 \mathrm{~min}$ & -2.331 & -1.701 & & & & \\
\hline \multicolumn{7}{|l|}{ Non-risky } \\
\hline $\mathrm{PAT}>15 \mathrm{~min}$ & & & 1.701 & 1.815 & & \\
\hline PAT $>15 \mathrm{~min}$ and delay time $<5 \mathrm{~min}$ & -2.38 & -1.514 & & & & \\
\hline Work start time & & & -4.327 & -3.122 & & \\
\hline During morning rush hour & & & & & 1.978 & 1.938 \\
\hline \multicolumn{7}{|l|}{ Work end time } \\
\hline Prior to evening rush hour & & & -5.018 & -2.911 & & \\
\hline$\mu$ & 3.079 & 3.689 & 4.512 & 4.01 & 5.364 & 2.722 \\
\hline Number of observations & 125 & & 125 & & 125 & \\
\hline $\mathrm{L}(0)$ & -137.327 & & -137.327 & & -137.327 & \\
\hline $\mathrm{L}(\mathrm{R})$ & 101.046 & & 110.436 & & 88.829 & \\
\hline $\mathrm{L}(\mathrm{F})$ & 91.557 & & 95.483 & & 78.202 & \\
\hline
\end{tabular}

In our models, there were three responses $\left(\mathrm{Y}_{\mathrm{i}}\right)$ coded as 0 , 1 , and 2. Since only three responses existed and $Y$ takes on the values $-1,0$, and 1 , the model contained two cut points (i.e., zero and $\mu$ ) to demarcate three ranges. Positive and negative estimates indicated higher and lower emphasis on announcements to the base case, respectively. It also should be noted that the variables listed in this table are the ones considered to be significant in the final model.

\section{Women's Behavior Modeling}

Table 2 lists the factors considered to be significant in women's models regarding the traffic information system. The following points list each of these factors and their explanations.

\section{Listening to Radio}

Results indicate that listening to the radio has a positive impact on propensity to use accident reports. It might be inferred that one reason women listen to the radio traffic reports is to be aware of recently-occurred crashes, since women are shown as more willing to avoid potential safety problems.

\section{Driving Time}

Longer total travel time indicates a lesser likelihood to listen to one type of the traffic reports (e.g., construction activities announcements), and it does not influence women's preference to use other reports. Since getting 
Table 3 Results of modeling men's propensity to pay attention to the announcements

\begin{tabular}{|c|c|c|c|c|c|c|}
\hline \multirow[t]{2}{*}{ Variable description } & \multicolumn{2}{|c|}{$\begin{array}{l}\text { Alternative route } \\
\text { announcement }\end{array}$} & \multicolumn{2}{|c|}{$\begin{array}{l}\text { Construction activity } \\
\text { announcement }\end{array}$} & \multicolumn{2}{|c|}{$\begin{array}{l}\text { Road accident } \\
\text { announcement }\end{array}$} \\
\hline & Coefficient & $\mathrm{t}$ value & Coefficient & $\mathrm{t}$ value & Coefficient & t value \\
\hline Constant & 8.846 & 3.335 & 3.442 & 3.191 & 3.257 & 2.269 \\
\hline Listening to Radio-Payam & 0.617 & 2.171 & 0.891 & 3.305 & 0.662 & 2.480 \\
\hline Income & 0.336 & 1.415 & & & & \\
\hline Driving time (Logarithm) & & & -0.689 & -2.592 & & \\
\hline Vehicle ownership & & & 1.256 & 2.070 & 1.319 & 2.090 \\
\hline Age (Logarithm) & -1.136 & -2.279 & & & & \\
\hline Older than 45 years & & & & & 0.377 & 1.322 \\
\hline \multicolumn{7}{|l|}{ Delay time } \\
\hline Any delay is permitted & & & -0.407 & -1.437 & & \\
\hline Delay time $16-30 \mathrm{~min}$ & 1.135 & 2.192 & & & & \\
\hline Delay time $>30 \mathrm{~min}$ & -1.442 & -1.692 & & & & \\
\hline \multicolumn{7}{|l|}{ Preferred arrival time } \\
\hline \multicolumn{7}{|l|}{ Risky } \\
\hline $\mathrm{PAT}<15 \mathrm{~min}$ and delay time $<5 \mathrm{~min}$ & 0.524 & 1.584 & -0.456 & -1.511 & & \\
\hline $\mathrm{PAT}<15 \mathrm{~min}$ and delay time $5-15 \mathrm{~min}$ & 0.834 & 2.410 & & & & \\
\hline \multicolumn{7}{|l|}{ Non-risky } \\
\hline $\mathrm{PAT}>30 \mathrm{~min}$ & 1.768 & 1.592 & & & & \\
\hline Work start time & -0.378 & -2.069 & & & -0.288 & -1.735 \\
\hline$\mu$ & 2.427 & 9.501 & 2.419 & 10.805 & 2.463 & 9.768 \\
\hline Number of observations & 279 & & 279 & & 279 & \\
\hline $\mathrm{L}(0)$ & -306.513 & & -306.513 & & -306.513 & \\
\hline $\mathrm{L}(\mathrm{R})$ & 231.930 & & 253.734 & & 237.176 & \\
\hline $\mathrm{L}(\mathrm{F})$ & 215.982 & & 243.005 & & 227.365 & \\
\hline
\end{tabular}

information on long trips does not cause perceptible change in travel time, this result was expected and logical.

\section{Education, Age and Occupation}

Results indicated that: (1) Young female drivers (between 18 and 30 years old) care about alternative route announcements most; (2) The more the driver is educated, the more tendency she has to listen to radio traffic reports; and (3) Company employees are more interested in highway construction announcements. The conclusion about education is consistent with the results of Jiang et al. [17].

\section{Preferred Arrival Time and Permitted Delay Time}

To examine how risk-taking behavior of drivers contributes to the use of traffic information, the coefficient of variables PAT and permitted delay as well as the combination of these two were reviewed in Table 2. Coefficient within all three women's models for variable PAT less than 15 min (i.e., -1.837) and its combination with delay time (i.e.,
$-3.214,-2.701$ and -2.331$)$, as the indicator of risky persons, reveals that smaller PAT makes it less likely to listen to the reports. Considering the sign and magnitude of those variables (PAT less than 15 and various delay times) in Table 2, it is identified that commuter's use of traffic information decreases proportional to the reduction in permitted delay time. In other words, female commuters displayed decreased likelihood to listen to traffic reports if they were more likely to take higher risks.

Results show that female drivers, who are permitted to have any delay time, have a much lower propensity to use incident reports (labeled -3.394 in Table 2). Findings suggest that female drivers select not to use reports due to their employer's leniency toward work shift arrival time or a nonexistent policy regarding late arrivals. The effect of permitted delay on using traffic information is also investigated by considering the sign and value of variable PAT more than $15 \mathrm{~min}$ in the construction activity model, combined with delay tolerance less than $5 \mathrm{~min}$ in the alternative route model. Non-risky females, who tend to arrive at the workplace more than $15 \mathrm{~min}$ early 
(PAT $>15)$, have a high propensity to be informed of construction activities in routes (1.701 is a positive coefficient). Similar findings has also been reported by Caplice and Mahmassani [25] who first considered PAT as a measure of risk aversion and an explanatory variable in traffic information use models. These women are more cautious and reluctant to pass the "under construction" roads. Female drivers will not pay attention to alternative route announcements if they are limited to have less than a five-minute delay.

\section{Work Start/End Time}

Both drivers with later work start times and early work end times (prior to peak traffic rush hour) give less attention to the construction activities announcements. During morning rush hour and afternoon rush hour, when the congestion is more likely, commuters have a higher propensity to listen to the accident reports.

\section{Men's Behavior Modeling}

Table 3 lists the factors considered to be significant in men's models regarding the traffic information system. The following points list significant factors in modeling men's behavior.

\section{Listening to Radio}

Typically, drivers who listen to the radio have a higher propensity to listen to these types of traffic announcements. Caplice and Mahmassani [25] in the U.S. and Emmrink et al. [11] in the Netherlands found a relatively similar result. Their studies indicated that regardless of sex, the more drivers listen to radio traffic information, the more likely they are to change their route choice due to radio traffic information. In Table 3 , a variable indicating listening to the radio emerged in all models developed for men. Its positive sign indicated that men who listen to radio traffic information rate reports, including alternative route, construction activity, and road accident announcements, found them important. Listening to the radio can be a representative of having trust in the accuracy of this system.

\section{Income}

Vehicle type/year variable is used as a "proxy" for income variable. It was found that men with higher income index put more importance on alternative route reports.

\section{Driving Time}

Similar to the women's model, travel time has a negative effect on listening to construction activity reports for men.

\section{Vehicle Ownership}

Male vehicle owners are more likely to be informed of accidents that recently occurred and construction activities than men who drive someone else's vehicles, such as rental cars or their family member's vehicles. In other words, owning a vehicle makes male drivers sensitive to navigate through construction routes where their cars may become damaged.

Age

Nonlinear effects of commuter age showed that older male commuters have a lower propensity to know about alternative routes. This suggests that as men age, they would become more resistant to change; however, commuters older than 45 take road incident announcements more seriously than those younger than 45 .

\section{Preferred Arrival Time}

Unlike the women's model results, risky male drivers (men with the short permitted delay and short PAT) have a high propensity to know alternative routes, but they appeared less likely to listen to construction activity reports. On the other hand, the percentage of women respondents with PAT less than $15 \mathrm{~min}$ is $85 \%$ and more than $15 \mathrm{~min}$ is $15 \%$, and for men is 73 and $27 \%$, respectively. In equal permitted delay times, women reported shorter PATs than men. It can be concluded that males are less willing to risk being late to work than females.

\section{Permitted Delay Time}

Similar to women, the allowance to arrive to work late has a negative effect on men's propensity to use traffic information. For male commuters, being permitted to be more than 30 min late causes less interest to know alternative paths.

\section{Work Start/End Time}

Results indicate that a male who starts working late takes advantage of lower congestion and puts less importance on the announcements (alternative routes and accidents). 


\section{Summary}

This study strived to identify whether or not differences occur in male and female drivers' propensities to use traffic information, such as alternative route, construction activity, and road accident announcements, through in-vehicle radio. A random sample of drivers was surveyed, and ordered response models, specifically the ordered logit model, were developed to investigate their behavior. This study adds to the current literature with regard to the following similarities and differences found in the drivers' behavior:

\section{Similarities}

- For both models, results indicate that drivers have a higher propensity to listen to the accident reports during morning rush hours.

- Long travel time has a negative effect on listening to construction activity reports.

- Younger commuters (both males and females) tend to change their routes more often than older commuters. This is inconsistent with the results from Zhong et al. [14], which indicated that youngsters are less willing to divert from initially determined routes, and with Kattan et al. [18] who showed that demographic factors do not have influence on changing decisions. But it is similar to the result of another study by Yan and $\mathrm{Wu}$ [29] that the older drivers are less willing to change driving routes under the VMS guidance.

- Lateness tolerance at the workplace has an important effect on both groups' propensity to use traffic information. Drivers who are permitted to have a long delay showed less interest to listen to the radio reports.

\section{Differences}

- Unlike the women model results, risky male drivers have a higher propensity to know alternative routes.

- In equal permitted delay times, women reported shorter PATs than men. It can be concluded that male risk acceptance to reach their workplace is less than females.

- While listening to the radio messages in modeling men, attention to radio reports was significant, but for women it only has effect on the route accident announcement. It shows that women are less likely to be influenced by traffic information. Similar results were found by Yan and $\mathrm{Wu}$ [29], which indicated that male drivers are more likely to be influenced by traffic information derived from VMS;
- If male drivers have a car, they would rate the routes that were under construction and the accident reports as more important, whereas vehicle ownership for women was not found determinant.

- In equal permitted delay times, women reported shorter PATs than men. It can be concluded that males are less willing to risk being late to work than females.

The final results showed that almost all variables in both men's and women's models were in common except education and occupation, which were identified as significant in the females' behavior only, and income and car ownership, which seemed meaningful on the males' choice. The conclusion about income was consistent with the results of past studies. Zhong et al. [14] and Jou et al. [22] found that the tendency to switch routes increased with the rise of monthly income and the sample they used was composed of both men and women respondents.

It is recommended that more questions be added to the survey about the type of traffic information that drivers consider important and prefer to listen to. With more specific results, more appropriate information could be broadcasted to meet their needs and improve the system performance. Radio-Payam must provide quantitative and prescriptive information, such as the expected additional delay due to construction activities or accidents on route and the expected travel time if used the alternative routes. The reports should be broadcasted more frequently, especially during the rush hours when drivers have higher tendency to listen to the radio. The system should provide early morning commuters with accurate information about accident reports because these drivers have a larger propensity to listen to this type of reports. Also, telephonebased services must support the radio system by providing customized information.

Since more and more women are getting driver's licenses and choosing to drive more often, further research into modeling their behavior is needed after adequate time has elapsed following the application of required changes in the system in order to investigate changes in their behavior and needs.

\section{References}

1. Mamdoohi AR, Kermanshah M (2005) Traffic information use modeling in the context of a developing country. Transp Eng 33(1-2): 125-137

2. Rosenbloom S (2006) Understanding women's and men's travel patterns. Research on women's issues in transportation: report of a conference. Transp Res Board, Washington, D.C., pp 7-28

3. Goddard TB, Handy SL, Cao X, Mokhtarian PL (2006) Voyage of the SS Minivan: women's travel behavior in traditional and suburban neighborhoods. Transp Res Rec 1956:141-148 
4. Nobis C, Lenz B (2004) Gender differences in travel patterns: role of employment status and household structure. Research on women's issues in transportation, report of a conference, Technical Papers 2:114-123

5. Meyers-Levy J, Maheswaran D (1991) Exploring the differences in males' and females' processing strategy. J Consum Res 18:63-70

6. Transportation Research Board (2004) Research on women's issues in transportation, report of a conference, volume 2. Illinois, Chicago

7. Clifton KJ, Dill J (2005) Women's travel behavior and land use: will new styles of neighborhoods lead to more women walking. In: Transportation research board conference proceedings no 35

8. Johnston-Anumonwo I (1992) The influence of household type on gender differences in work trip distance. Prof Geogr 44:161-169

9. Hanson S, Johnston I (1985) Gender differences in work-trip length: explanations and implications. Urban Geogr 6:193-219

10. McGuckin N, Zmud J, Nakamoto Y (2005) Trip-chaining trends in the United States: understanding travel behavior for policy making. Transp Res Rec 1917:199-204

11. Emmerink RH, Nijkamp P, Rietveld P, Van Ommeren JN (1996) Variable message signs and radio traffic information: an integrated empirical analysis of drivers' route choice behavior. Transp Res A 30(2):135-153

12. Bagloee SA, Ceder A, Bozic C (2014) Effectiveness of en route traffic information in developing countries using conventional discrete choice and neural-network models. J Adv Transp 48(6):486-506

13. Tseng YY, Knockaert J, Verhoef ET (2013) A revealed-preference study of behavioural impacts of real-time traffic information. Transp Res C 30:196-209

14. Zhong S, Zhou L, Ma S, Jia N (2012) Effects of different factors on drivers' guidance compliance behaviors under road condition information shown on VMS. Transp Res A 46(9):1490-1505

15. Gan HC, Bai Y, Wei J (2013) Why Do People Change Routes? Impact of Information Services. Ind Manag Data Syst 113(3):403-442

16. Khoo HL, Ong GP (2011) Analysis of awareness and use of traffic information system with revealed preference data case. Transp Res Rec 2239:101-111

17. Jiang G, Zheng Z, Bai Z, Dai L, Zhao J (2006) Survey and analysis of driver's response to dynamic traffic information. In:
The 9th international IEEE conference on intelligent transportation systems (ITS)

18. Kattan L, de Barros AG, Saleemi H (2013) Travel behavior changes and responses to advanced traveler information in prolonged and large-scale network disruptions: a case study of west LRT line construction in the city of calgary. Transp Res Part F 21:90-102

19. Bonsall PW (1992) Acceptance of route guidance advice: an international comparison. In: Proceedings of the international conference on V.N.I.S., Oslo, pp 617-625

20. Bonsall P W, Merrall A C (1996) Analysing and modelling the influence of roadside variable message displays on drivers' route choice. Volume 1: travel behavior. World Transport Research. In: Proceedings of the 7th world conference on transport research

21. Wardman M, Bonsall PW, Shires JD (1997) Driver response to variable message signs: a stated preference investigation. Transp Res C 5(6):389-405

22. Jou RC, Lam SH, Liu YH, Chen KH (2005) Route switching behavior on freeways with the provision of different types of realtime traffic information. Transp Res A 39:445-461

23. Darzi-Ramandi A, Kermanshah M (2006) Willingness to pay for travel information M.S.C Thesis, Sharif University of Technology, Tehran

24. Memarian A, Kermanshah M (2008) Developing choice models to improve radio travel information system. In: 4th national congress of civil engineering, NCCE-4, Tehran University, Tehran

25. Caplice C, Mahmassani HS (1992) Aspects of commuting behavior: preferred arrival time, use of information and switching propensity. Transp Res A 26(5):409-418

26. Grilli L, Rampichini C (2014) Ordered logit model. In: Michalos $\mathrm{AC}$ (ed) Encyclopedia of quality of life and well-being research. Springer, Dordrecht, pp 4510-4513

27. Daykin AR, Moffatt PG (2002) Analyzing ordered responses: a review of the ordered probit model. Underst Stat 1(3):157-166

28. Greene W (2008) NLogit 4 user's guide Inc. Prentice Hall, Upper Saddle River, pp 1986-2007

29. Yan X, Wu J (2014) Effectiveness of variable message signs on driving behavior based on a driving simulation experiment. Discret Dyn Nat Soc, 2014: Article ID 206805 